\title{
Grafting Methods for Watermelon Production
}

\author{
Richard L. Hassell ${ }^{\mathbf{1}}$ and Frederic Memmott \\ Clemson University, CREC, 2700 Savannah Highway, Charleston, SC 29414 \\ Dean G. Liere \\ Syngenta Seeds, Inc., 5355 Monterey Frontage Road, Gilroy, CA 95020
}

Additional index words. cucurbit, rootstock, scion

\begin{abstract}
Vegetable grafting is most common in European and Asian countries where crop rotation is no longer an option and available land is under intense use. Grafting is an alternative approach to reduce crop damage resulting from soilborne pathogens and increase plant abiotic stress tolerance, which increases crop production. We discuss and outline four grafting methods that are available for vegetable production in cucurbits: tongue approach grafting, hole insertion grafting, one cotyledon grafting, and side grafting.
\end{abstract}

The initial grafting method used for melon was cleft grafting (Ishibashi, 1959), but after the introduction of the tongue approach grafting method, its use diminished greatly. The tongue approach method became widespread in Asia because of its higher success rate and the uniform growth of grafted seedlings. In Italy, the most common have been the approach and cleft methods (Bianco, 1990; Buzi et al., 2002; Morra, 1997), but currently the one cotyledon method and the hole insertion method are used (Amadio, 2004). In Spain, a high proportion (more than 90\%) of watermelon plants are grafted using the one cotyledon method (Miguel and Maroto, 2000). In France, both the side insertion and the tongue approach have been used in cucurbits (Brajeul and Letard, 1998). Top insertion grafting is the most popular method used in China, because it is suitable for Lagenaria and interspecific squash as rootstocks and requires few materials, has a high efficiency, $1500+$ plants/day/worker, and simpler management requirements (Lee and Oda, 2003).

\section{GRAFTING TECHNIQUES}

There are two techniques used in grafting, manual and machine (robotic grafting). In manual grafting, the grafting and postgrafting operations require three to four people, each assigned to a specific step in the process (Lee and Oda, 2003). Cucurbits are usually grafted once the first true leaf appears but before it reaches full development both in the rootstock and scion seedlings. To reach this stage for both the scion and the rootstock, planting dates will vary depending on the rootstock and scion chosen, greenhouse temperatures, and seed germination criteria. Different grafting approaches have been adapted depending on scion and rootstock purpose, grafting technique, grower experience, and postgrafting management condition. The tongue approach, hole insertion, and one cotyledon grafting are the currently preferred methods. Modifications to these methods have been

${ }^{1}$ To whom reprint requests should be addressed; e-mail rhassel@clemson.edu done by growers adapting to their particular operation. The tongue approach technique, which has a high survivor rate in general, is chosen by nonexperienced farmers who are looking into grafting for the first time and have plenty of space and adequate labor. One cotyledon and hole insertion grafts require specialized tools and a healing chamber for a high survivor rate and require time to learn. In addition, the graft junction needs to be aboveground during grafting and healing to avoid the direct contact between the scion and soil because adventitious root are easily stimulated, which will defeat the purpose of the graft.

In automatic (machine-driven) grafting, the requirements for the growth of the rootstock and scion are just as critical as in manual grafting. Uniformity in both germination and growth of the rootstock and scion are more critical for the robotic-driven machines. Machine grafting is done using a simple machine or a grafting robot, which is expensive. New machines are currently being developed in Japan and Korea that are much more forgiving and require less labor to operate. The grafting method generally used by these machines is the one cotyledon graft. It is well adapted for machine operation and has a high rate of success. However, there are constant adjustments being made to the machine at the cutting arm to adjust for the variation in hypocotyl thickness or lack thereof. Removal of one of the cotyledons from the hypocotyl at just the right depth and angle is critical for the take of the graft and also for preventing shoot development from the rootstock. The first semiautomatic grafting system for cucumber was commercialized in 1993 and numerous others have been developed since then. A simple grafting machine can produce 600 grafts per hour with two operators as compared with manual grafting making $\approx 1000$ grafts per person per day (Lee and Oda, 2003; Masanao and Hisaya, 1996; Suzuki et al., 1998). In Spain, the automated methods represent less than the $5 \%$ of the total cucurbits but may be as high as $10 \%$ in Japan and China. At present, $40 \%$ of watermelon grafting in Japan is done by the automated method (Lee and Oda, 2003; Masanao and Hisaya, 1996; Suzuki et al., 1998).

\section{MATERIAL AND GRAFTING METHODS}

Quality seed and proper plant growth procedures of both rootstocks and scion material are critical for grafting to be successful. High-quality seed with a uniform germination is a must. If primed seed is available, take advantage of it. This seed germinates sooner and with greater uniformity. If seedless watermelon seed is used as the scion material, use the methods for uniform seed germination described by Hassell and Schulthesis (2002). Rootstock seed is generally sown 5 to $7 \mathrm{~d}$ before scion seed regardless if they are grown in cell trays or germination beds. The cotyledon of rootstocks should be fully expanded when the scion emerges, keeping the scion at low relative humidity before grafting can minimize pathogen diseases. Watermelon scion are harvested (1 or 2 d) after they emerge, rinsed with clean water, and then treated with fungicides or disinfectant, e.g., Physan 20 or peroxyacetic acid/hydrogen peroxide, to minimize the microorganism damage to the graft. The rootstock should have good tolerance to abiotic stress, resistance to soilborne diseases, and not negatively affect fruit quality. The compatibility between rootstock and scion should be high and stable. In general, grafting compatibility is related to taxonomic affinity. For example, luffa and melon have higher compatibility with nettle melon compared with chinese pumpkin and wax gourd (Wei et al., 2006). Grafting incompatibility can occur at an early stage because vascular connection cannot form properly after grafting. Grafting incompatibility can also be delayed until fruiting stage when massive amounts of nutrition and water are needed. Grafted plants then decline early and successful harvesting is impossible. There is a positive correlation between the vigor of grafted watermelon and the similarity of protective isozymes, e.g., peroxidase and superoxide dismutase, between grafted and regular seedlings (Zhang et al., 2006). The age of the rootstock and scion also plays an important role in compatibility. Optimal seedling age varies for species and different grafting methods. If seedlings are too young, they are too tender to handle during the grafting process and if they 
are too old, it can cause unwanted meristematic growth on the rootstock.

Once grafting has taken place and the necessary procedures followed, the proper healing chamber is critical to ensure that complete union has formed. With the case of the tongue approach grafting, this means only an adequate greenhouse with temperatures controls. However, for the other three methods described, a special healing chamber with light, humidity, and temperature controls are required. Some nurseries, producing grafted plants, have chambers (growth chambers or healing chambers) to maintain temperature above $20{ }^{\circ} \mathrm{C}$ to $\approx 25{ }^{\circ} \mathrm{C}$ with relative humidity ( $\mathrm{RH}$ ) controls maintained between $85 \%$ and $100 \%$ (Miguel, 1997). Other nurseries acclimate in small plastic tunnels (healing chamber) inside the greenhouses where it is possible to maintain a high RH (above $85 \%$ ). Shading is often required during summer months when using a healing chamber. After 6 to $8 \mathrm{~d}$, grafted plants are acclimated to the natural conditions of the greenhouse by slowly dropping the humidity and increasing light. The best conditions for grafting are: temperatures of $\approx 22$ to $28{ }^{\circ} \mathrm{C}$, RH close to $100 \%$, and very low light intensity for the first 5 to $7 \mathrm{~d}$ (Miguel, 1997). Humidifiers can be purchased; however, remember that too much free water can lead to disease pressure and loss of graft union. A fog or mist system is the preferred method.

Listed subsequently are the current methods and figures of each being tested for grafting watermelon transplants. In all the methods described subsequently, the scion seed should be sown at different intervals from the rootstock seed depending on greenhouse conditions, germination temperatures, and rootstock seed chosen. As a general rule, the rootstock seed germinates quicker that the scion seed. This procedure is followed to ensure that the physiological development of the scion and rootstock is as close to the same as possible.

Tongue approach grafting. Cell size for growing the transplants for both the scion and rootstock is $2.5 \mathrm{~cm}$ square and $5 \mathrm{~cm}$ deep. After rootstock has fully developed cotyledons and scion has cotyledon and first true leaf, plants are pulled out from the tray and laid on a table (Note: $1 \mathrm{~d}$ before doing the grafting, trays should be watered heavily.). Do an angle ( $35^{\circ}$ to $45^{\circ}$ angle) cut into the hypocotyl of rootstock approximately halfway with a razor blade and make an oppositely angled cut on the hypocotyl of the scion (Fig. 1A). These cuts need to be made so that the scion will be on top of the rootstock when completed (Fig. 1C). Two cut hypocotyls are placed together, then sealed with aluminum foil to help healing and prevent the graft from drying out (Fig. 1D). The two plants are then transplanted into a bigger cell that will accommodate the two root balls $(5 \mathrm{~cm}$ square $\times 7.5 \mathrm{~cm}$ deep $)$. Trays are then watered heavily until soil is completely wet. Trays should then be moved into a greenhouse (Note: After trays have been placed in the greenhouse, water only as needed.). The top of the rootstock is cut off $5 \mathrm{~d}$ after grafting (Fig. 1D), and the bottom of the scion is cut off $7 \mathrm{~d}$ after the top of the rootstock is removed (Fig. 1E). After the bottom of the scion is cut off, you must wait $2 \mathrm{~d}$ for the plants to be ready to transplant. Grafted plants are maintained in the greenhouse until the plants are ready for transplanting. Grafted plants need not be maintained in high humidity after grafting; plants should not be older than $33 \mathrm{~d}$ before transplanting.

Hole insertion grafting. Rootstock seeds are sown in a 3- to $4-\mathrm{cm}$ square cell $5 \mathrm{~cm}$ deep. Scion seeds are sown in a much smaller cell tray (1- to $2-\mathrm{cm}$ cell $5 \mathrm{~cm}$ deep) with multiple seeds per cell. Trays for rootstock should be watered very well and trays for triploid scion should be watered to the best moisture for germination (Hassell and Shulthesis, 2002). Trays are maintained at $30{ }^{\circ} \mathrm{C}$ for germination. When both cotyledons and first true leaf start to develop, the rootstock plant is ready to graft $(\approx 7$ to $10 \mathrm{~d}$ after sowing), depending on greenhouse conditions. Remove the growing point with a sharp probe, and then open a hole on the upper portion of the rootstock hypocotyl (Fig. 2BC). A bamboo needle or $1.4-\mathrm{mm}$ drill bit

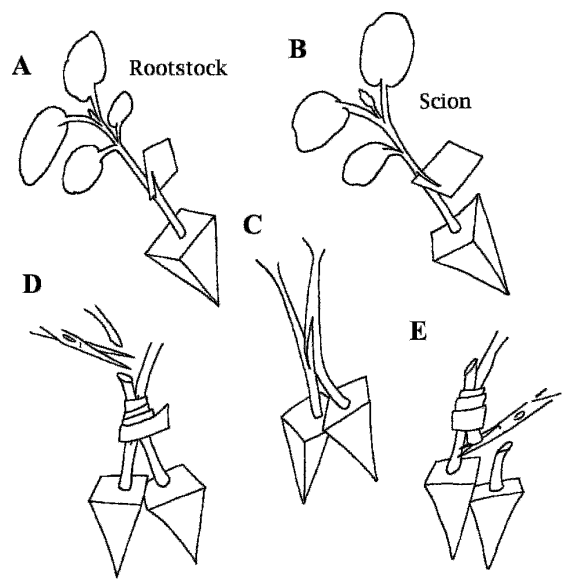

Fig. 1. Tongue approach grafting.

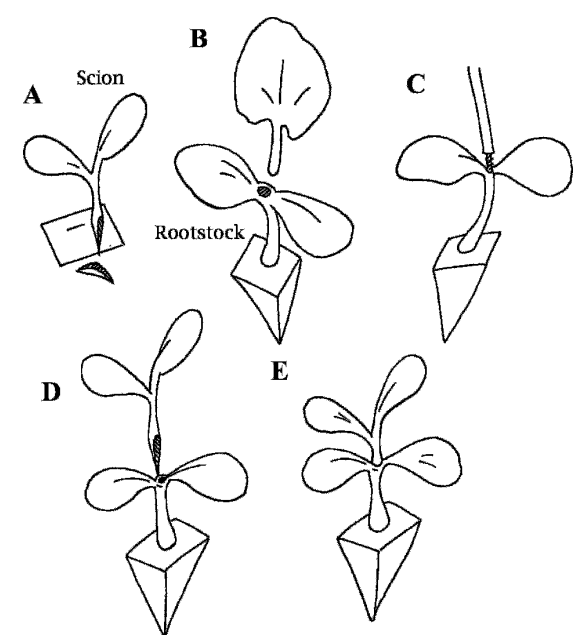

Fig. 2. Hole insertion grafting. works best. The scion is then cut on a $35^{\circ}$ to $45^{\circ}$ angle, both sides, on the hypocotyls (Fig. 2A). The scion is then inserted into the hole made in the rootstock (Fig. 2D). The cut surfaces are matched together and held with or without a grafting clip (Fig. 2E). Grafted plants should then be transferred to a humidity chamber or healing room. After the healing process is complete, grafted plants are then transferred and maintained at 21 to $36^{\circ} \mathrm{C}$ in the greenhouse until the scion is connected well with the rootstock; plants should not be older than $33 \mathrm{~d}$ before transplanting.

One cotyledon grafting. Production of rootstocks and scions is the same as described for hole insertion grafting. When both cotyledons and first true leaf start to develop, the rootstock plant is ready to graft $(\approx 7$ to $10 \mathrm{~d}$ after sowing). One cotyledon, along with the visible growing point, is cut with a razor blade following the angle of the leaf petiole (Fig. 3B). The hypocotyl of the scion is cut on a $35^{\circ}$ to $45^{\circ}$ angle (Fig. 3A) on one side only. The two cut surfaces are matched and held together with a grafting clip or a silicone sleeve (Fig. 3C-D). Grafted plants should then be transferred to a humidity chamber or healing room. Postgrafting care is the same as that described for hole insertion grafting.

Side grafting. Production of rootstocks and scions is the same as that described for hole insertion grafting. When both cotyledons and first true leaf start to develop, the rootstock plant is ready to graft $(\approx 7$ to $10 \mathrm{~d}$ after sowing). A slit is cut on the hypocotyl of the rootstock with a razor blade and held open with a toothpick (Fig. 4B-C). An angle cut, $35^{\circ}$ to $45^{\circ}$ angle, on both sides is done on the hypocotyl of the scion (Fig. 4A). The scion is then inserted into the slit in the hypocotyl of the rootstock and the toothpick is removed (Fig. 4D). Two cut surfaces are matched together and held with a grafting clip or silicone sleeve (Fig. 4D). Grafted plants should then be transferred to a humidity chamber or healing room. The top of the rootstock is cut off $5 \mathrm{~d}$ after grafted plants are moved from the high-humidity growth chamber (Fig. 4E). Plants are maintained in the greenhouse until the scion is connected well

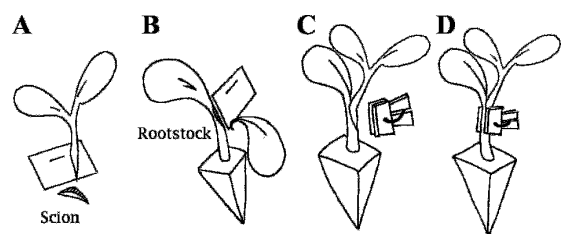

Fig. 3. One cotyledon grafting.

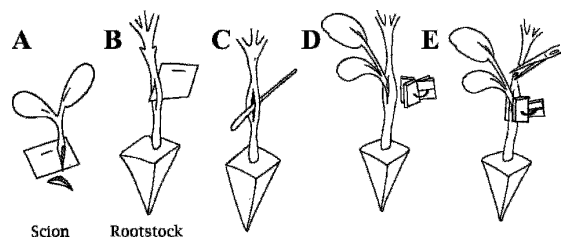

Fig. 4. Side grafting. 
to the rootstock; plants should not be older than $33 \mathrm{~d}$ before transplanting.

\section{Literature Cited}

Amadio, A. 2004. Alternatives to methyl bromide adopted for cucurbit production in projects funded by Montreal Protocol. Proc. Fifth International Conference on Alternatives to Methyl Bromide, Lisbon. p. 71-74.

Bianco, V.V. 1990. Melon (Cucumis melo L.). In: Orticoltura, Pàtron ed., Bologna. p. 564-609.

Brajeul, E. and M. Letard. 1998. La filiere experimentation concombre. PHM 396:48-50.

Buzi, A., G. Chilosi, R. Reda, and P. Magro. 2002. Le principali fitopatie che colpiscono il melone. Colt. Prott. 9:31-45.
Hassell, R. and J. Schulthesis. 2002. Seedless watermelon transplant production guide. 1 Feb. $2004<$ http://www.clemson/psapublishing/ ppt_files/Seedlesswatermelon.ppt>.

Ishibashi, K. 1959. Cucumber cultivation using grafting [in Japanese]. Agr. Hort. 4:343-347.

Lee, J.M. and M. Oda. 2003. Grafting of herbaceous vegetable and ornamental crops. Hort. Rev. (Amer. Soc. Hort. Sci.) 28:61-124.

Masanao, U. and Y. Hisaya. 1996. Development of full automatic grafting robot for fruit vegetables. Robot Tokyo. 109:59-65.

Miguel, A. 1997. Injerto de hortalizas. Ed Generalitat Valenciana. Conselleria de Agricultura, Pesca y Alimentación.

Miguel, A. and J.V. Maroto. 2000. Nuevas técnicas en el cultivo de la sandía [Citrullus lanatus
(Thunb.) Matsum. and Nakai]. Ed. Consellería de Agricultura, Pesca y Alimentación de la Generalitat Valenciana y Fundación Ruralcaja.

Morra, L. 1997. L'innesto erbaceo coltura per coltura. Colture Protette. 5:17-22.

Suzuki, M., S. Sasaya, and K. Kobayashi. 1998. Present status of vegetable grafting systems. Japan Agr. Res. Quarterly 32:105-112.

Wei, S.Y., Z. Wu, and J. Huang. 2006. Effects of rootstocks on growth and photosynthetic properties of grafted plants of netted melon. Acta Agriculturae Shanghai 22:114 117.

Zhang, Z.X., A.Q. Li, Y.L. Xu, and Y.J. Xu. 2006. Analysis of plant protecting isozymes and their affinity of grafted watermelon seedlings. Chinese Journal of Tropical Crops 27:12-16. 